\title{
Metal-Responsive Regulation of Enzyme Catalysis using Genetically Encoded Chemical Switches
}

\author{
Yasmine S. Zubi, ${ }^{\ddagger}$ Kosuke Seki, ${ }^{\sharp \#}$ Ying Li, ${ }^{\S}$ Andrew Hunt, ${ }^{\dagger}$ Bingqing Liu, ${ }^{\ddagger}$ Benoît \\ Roux, ${ }^{\S *}$ Michael C. Jewett, ${ }^{\dagger *}$ Jared C. Lewis ${ }^{\ddagger *}$ \\ ${ }^{\ddagger}$ Department of Chemistry, Indiana University, Bloomington, Indiana 47405, United \\ States \\ ${ }^{\dagger}$ Department of Chemical and Biological Engineering and Center for Synthetic Biology, \\ Northwestern University, Evanston, IL, 60208, USA \\ §Department of Chemistry, University of Chicago, Chicago, IL, 60637, USA \\ ${ }^{\#}$ These authors contributed equally to this study \\ *To whom correspondence should be addressed
}

\begin{abstract}
The design of allosteric regulation in proteins to dynamically control function is a challenge in synthetic biology. To address this challenge, we developed an integrated computational and experimental workflow to incorporate a metal-responsive chemical switch into proteins. Pairs of bipyridinylalanine (BpyAla) residues were genetically encoded into two structurally distinct enzymes, a serine protease and firefly luciferase, so that metal coordination would bias the conformations of these enzymes, leading to reversible control of activity. MD-simulations guided rational BpyAla placement, significantly reducing experimental workload, and cell-free protein synthesis coupled with high-throughput experimentation enabled rapid prototyping of variants. Ultimately, this strategy yielded enzymes with a robust 20 -fold dynamic range in response to divalent metals over 24 on/off switches, demonstrating the potential of this approach. We envision that this strategy of genetically encoding chemical switches into enzymes will complement other protein engineering and synthetic biology efforts, enabling new opportunities for applications where precise regulation of protein function is critical.
\end{abstract}

\section{Introduction}

Naturally occurring enzymes have evolved to catalyze chemical reactions, in many cases, with exquisite selectivity, substrate specificity, and high catalytic rates. ${ }^{1}$ Many enzymes also possess regulation and control mechanisms to ensure that they can respond to environmental stimuli (e.g., allostery). ${ }^{2}$ Leveraging these remarkable properties for chemical synthesis has long appealed to chemists and synthetic biologists, ${ }^{3,4}$ but current enzyme engineering strategies largely focus on improving catalytic properties or changing substrate specificity. ${ }^{5}$ These engineering strategies often neglect native control capabilities like allosteric regulation, which can be inefficient for nonnative substrates, ${ }^{6}$ or lost without selection pressure as has been observed in several directed evolution approaches $^{7-10}$.

A key challenge to engineering allosterically regulated enzymes is the complex interplay between catalytic activity, substrate specificity, and regulation. For example, while native allosteric proteins have been engineered to respond to new stimuli, this control typically applies to the native protein function, frequently DNA binding ${ }^{6,11}$ In addition, chimeric systems have been developed to couple allosteric regulation by a naturally responsive protein to an enzyme of interest, ${ }^{12}$ but large (potentially disruptive) regulatory domains must often be used, ${ }^{1,14}$ and achieving efficient 
regulatory transduction between domains requires extensive protein engineering ${ }^{15}$. Finally, while de novo design has been used to produce switchable proteins, ${ }^{16,17}$ switching has only been reported in response to peptides and proteins, and de novo design of switchable enzymes has not been reported. Modular, functionally-orthogonal methods to control enzyme activity in a stimulus-dependent manner ${ }^{18}$ could greatly improve the utility of engineered proteins for a variety of applications, including multi-enzyme cascade catalysis ${ }^{3}$, diagnostics, ${ }^{19}$ and artificial signaling circuits $^{20}$.

We envisioned that small molecule switches could be integrated into enzymes to enable regulation of catalysis. These switches undergo reversible formation or cleavage of covalent bonds in the presence of different stimuli. For example, boronic acids and diols form boronic esters at low $\mathrm{pH},{ }^{21}$ hydrazines and aldehydes form hydrazones in the presence of anilines, ${ }^{22}$ and bipyridines bind metal ions to form bis- or tris-bipyridine complexes ${ }^{23}$. We reasoned that amber codon suppression methods ${ }^{24}$ could be used to genetically encode non-canonical amino acids (ncAAs) that contain the reactive functional groups (linking groups, LGs) found in synthetic switches. Recent studies have shown that ncAAs can be used to control enzyme activity, ${ }^{25,26}$ although most examples rely on irreversible mechanisms like deprotection of caged residues ${ }^{27,28}$. Key to our approach, is the use of LGs to control protein conformation in ways that mimic native allosteric systems, ${ }^{2}$ enabling reversible control over protein function. LG incorporation would involve minimal disruption of protein structure with no fundamental limits on which proteins and activities could potentially be controlled. The structural simplicity of the LG approach, however, belies the potential difficulty of engineering systems in which two LGs impart suitable switching properties.

To address this difficulty, we developed a framework to design, build, test, and analyze enzymes with genetically encoded chemical switches. Initial efforts focused on bipyridine (Bpy) LGs that could induce reversible activation of enzymes in the presence/absence of metal salts (Figure 1a). Our framework (Figure 1b) used molecular dynamics (MD) simulations to identify all residue pairs that undergo significant changes in $\mathrm{C}_{\beta}$ distance during catalysis. Enzyme variants containing $L G$ pairs at candidate sites were then designed and rapidly prototyped using cell-free protein synthesis (CFPS) ${ }^{29}$ and high-throughput experimentation (HTE) to select functional candidates for analysis. Using this approach, we were able to engineer metal-responsive ${ }^{30}$ variants of two distinct enzymes, complementing methods for tuning enzyme catalysis and providing a means to genetically encode functionally orthogonal control elements to regulate enzyme catalysis. 

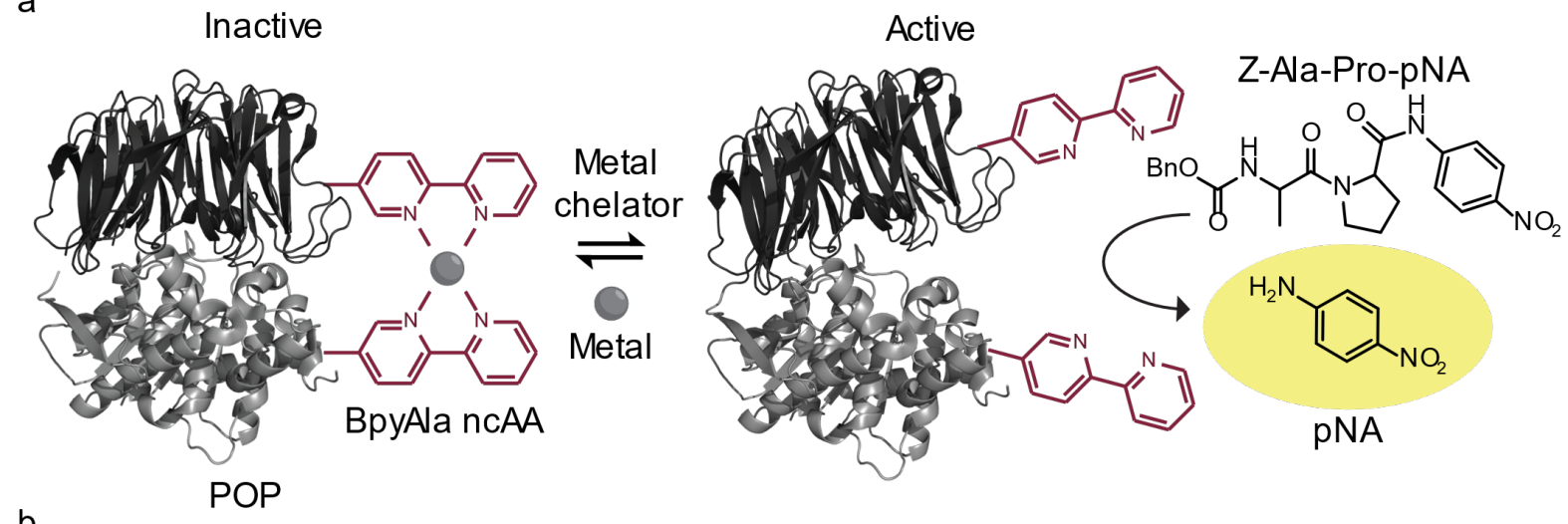

b

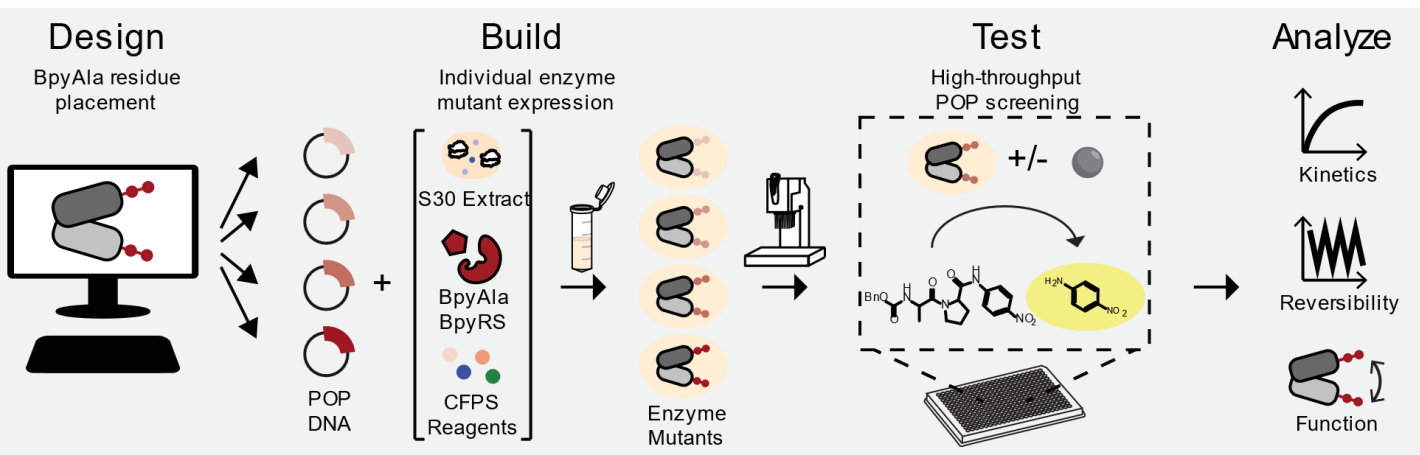

Figure 1. Development of BpyAla LG protein switches. (a) Reversible metal regulation of Pfu prolyl oligopeptidase (POP) by a BpyAla LG pair. (b) Workflow for engineering LG protein switches.

\section{Results}

\section{Model selection and design of POP switches}

Allosteric modulation of enzyme activity requires an enzyme that can adopt at least two states possessing different activity. ${ }^{2}$ By perturbing the populations of these states via covalent bond formation and cleavage under different conditions, LGs could be used to regulate enzyme activity in a stimulus-responsive manner. We selected prolyl oligopeptidase (POP), from the hyperthermophilic organism Pyrococcus furiosus (Pfu) as a model test case for LG regulation of enzyme activity. POP is a serine protease that hydrolyzes small peptide substrates containing proline residues, ${ }^{31}$ and it is not subject to native allosteric regulation. The POP structure comprises a $\beta$-propeller domain that controls substrate access to the active site and a peptidase subunit that contains a Ser-His-Asp catalytic triad. MD simulations revealed that POP undergoes spontaneous domain opening/closing that provides a dynamic port of entry for substrates and orients the catalytic triad His residue into a catalytically competent position. ${ }^{32}$ Suitably placed LGs could therefore provide a means to control POP conformation and peptidase activity. 

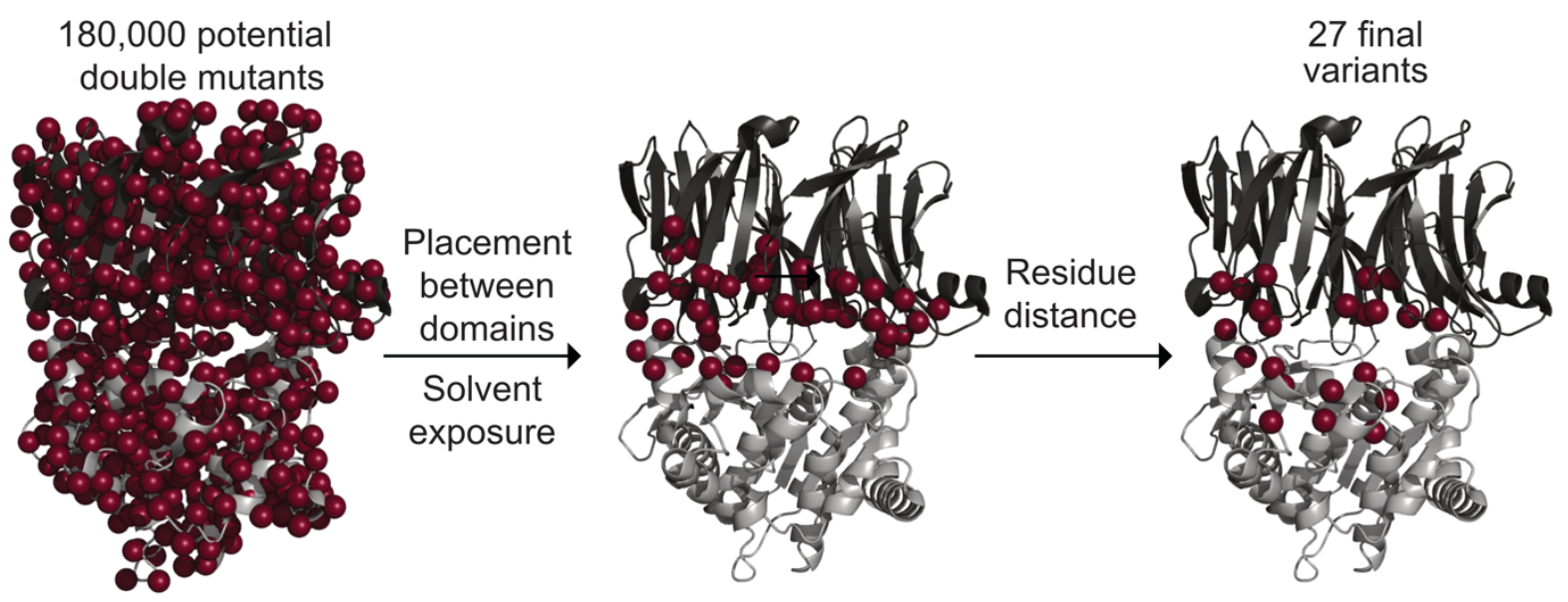

b

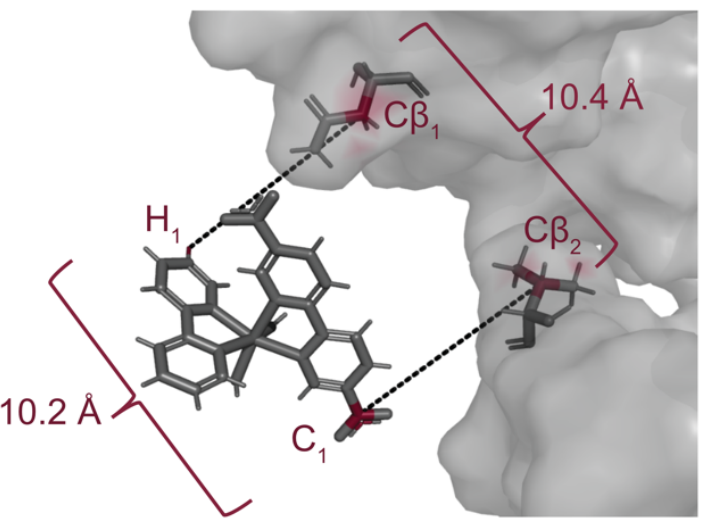

c

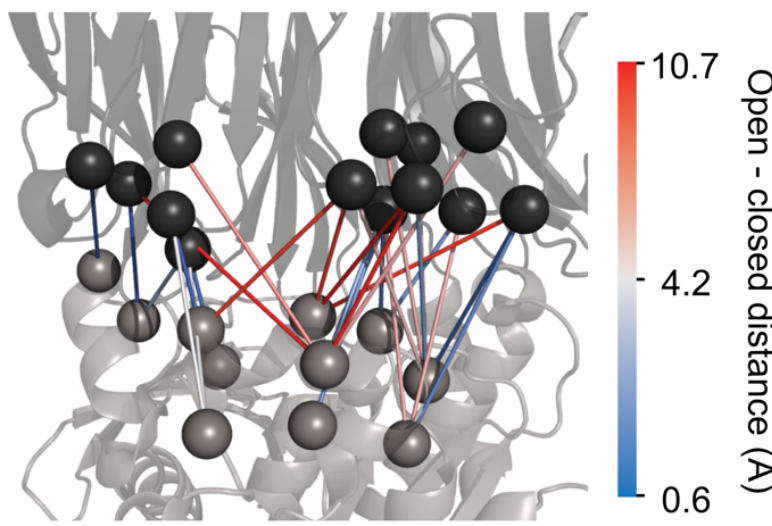

Figure 2. Design strategy for Bpy-Ala POP variants. (a) Filtering process used to select sites for Bpy LG pairs. (b) Distance and geometry requirements for Bpy LG placement highlighted by mapping the structure of a $\mathrm{Zn}(\mathrm{Bpy})_{2}$ (CCDC:756656) complex onto the Pfu POP structure. (c) Locations of the final 27 LG pairs. The spheres represent the positions of the $C \beta$ atoms of the selected residues on the $\beta$-propeller (black) and peptidase (grey) domains. Lines are drawn between residues in each pair, and the color of the line represents the change in distance between the residues in the open and closed POP conformations.

POP is a $72 \mathrm{kDa}$ protein with 180,000 possible double variants, and many proteins of interest could have a similarly large number of potential LG site pairs. Thus, we next developed a computationally guided approach for identifying sites for LG incorporation that could be applied to any protein. MD simulations were used to identify residues that (i) are close enough in space to enable covalent bond formation between LG pairs in one enzyme conformational state, (ii) are solvent exposed, and (iii) undergo changes in $\mathrm{C}_{\beta}$ distance suitable to prohibit bond formation in another conformational state (Figure 2a). These criteria decreased the residues considered to only surface exposed residues on opposite sides of the domain interface of POP. Because we were targeting metal regulation using genetically encoded bipyridinylalanine (BpyAla) residues, ${ }^{33}$ the structure of a $\mathrm{Zn}(\mathrm{Bpy})_{2}$ complex was analyzed to establish that a distance of approximately $10.5 \AA$ would allow for formation of a metal bis-BpyAla complex, M(BpyAla) $)_{2}$, at the interface of the $\beta$-propeller and peptidase domains of POP (Figure $2 b$ ). Residues with distances from 9.5$11.5 \AA$ between $C_{\beta}$ were selected and ranked according to the change in $C_{\beta}$ distances observed during the simulations (Figure 2c), and 27 LG pairs were selected for evaluation.

\section{HTE screening of POP switches}

We developed a three-step, HTE approach in which all computationally designed POP variants could be synthesized and screened for regulation by metal ions (Figure 1b). First, an E. coli-based 
CFPS platform ${ }^{29,34-36}$ was developed for synthesizing proteins containing two BpyAla residues in response to the amber stop codon. BpyAla and aminoacyl-tRNA synthetase (BpyRS) ${ }^{33}$ concentrations were combinatorially optimized using a sfGFP reporter containing two premature amber stop codons (2TAG-sfGFP) to enable 2TAG-sfGFP expression at yields comparable to WT sfGFP, and BpyAla incorporation was verified by intact protein ESI-MS (Supplementary Figure 1). Second, we synthesized the entire panel of $P O P$ variants $\left(P O P_{X Y Y}\right.$, where $X$ and $Y$ are the sites of BpyAla incorporation) at an average yield of $1098+/-124 \mu \mathrm{g} / \mathrm{mL}$, comparable to wild-type (WT) protein (Supplementary Figure 2). All POP variants were synthesized at full-length as measured by autoradiography of ${ }^{14} \mathrm{C}$-labelled proteins, and accurate incorporation of the BpyAla pair was further confirmed by intact protein ESI-MS (Supplementary Figure 2). Third, we designed a screening workflow that involved high-throughput liquid-handling to set up 384-well plate enzyme assays using POP-enriched CFPS reactions (diluted to be equimolar using blank CFPS reactions). POP activity and metal responsiveness was measured spectrophotometrically by monitoring $p$-nitroaniline ( $\mathrm{pNA}$ ) released by enzymatic hydrolysis of a dipeptide containing Cterminal pNA moiety (Figure 1a) ${ }^{31}$. The HTE workflow is purification-free and could enable screening and characterization of hundreds of enzyme variants and reactions in less than a day.

We first used this workflow to screen POP variants for $\mathrm{Ni}(\mathrm{II})$ inhibition by conducting the chromogenic assay outlined above in the presence of $0-1,000$-fold molar excess of $\mathrm{Ni}(\mathrm{II})$ relative to enzyme (Figure 3a). Control reactions indicated that blank CFPS extracts and 2TAG-sfGFP were inactive, and no background inhibition of WT POP occurred at any Ni(II) concentration. All but three POP variants, on the other hand, displayed activities towards Z-Ala-Pro-pNA, and 10 showed enzymatic rates at $>50 \%$ of WT activity. Eleven variants showed dose-dependent inhibition by $\mathrm{Ni}(\mathrm{II})$, and three, $\mathrm{POP}_{167 / 517}, \mathrm{POP}_{169 / 510}$, and $\mathrm{POP}_{159 / 517}$, displayed nearly complete inhibition at higher concentrations of $\mathrm{Ni}$ (II) (Figure $3 \mathrm{a}$, red). We also observed a range of sensitivities towards $\mathrm{Ni}(\mathrm{II})$ throughout the set of POP variants. For example, $\mathrm{POP}_{167 / 517}$ and $\mathrm{POP}_{159 / 517}$ showed a 10 -fold and 2.8-fold decrease in rate, respectively, at 100 -fold excess metal, while POP $156 / 513$ showed nearly no inhibition at the same concentration of metal. Interestingly, we also found two variants, $\mathrm{POP}_{167 / 513}$ and $\mathrm{POP}_{170 / 513}$, that were activated by $\mathrm{Ni}(\mathrm{II})$, rather than inhibited, which ran contrary to our original hypothesis. Additionally, the proximity of $167 / 517$ and $167 / 513$ in primary sequence space highlights how subtle changes in protein structure can have significant impacts on function (i.e., metal inhibition and activation, respectively) and the relatively unexplored space in understanding allosteric effects on protein function.

We next used this workflow to characterize $\mathrm{POP}_{X / Y}$ response toward different divalent metal cations, including $\mathrm{Cu}(\mathrm{II}), \mathrm{Co}(\mathrm{II})$, and $\mathrm{Zn}(\mathrm{II})$. While WT POP did not respond to any metals, POP variants that responded to $\mathrm{Ni}(\mathrm{II})$ also responded to $\mathrm{Cu}(\mathrm{II}), \mathrm{Co}(\mathrm{II})$, and $\mathrm{Zn}$ (II) in a dose-dependent manner (Supplementary Figure 3). The identity of the metal resulted in slight changes to the degree of inhibition and activation of the POP variants. For example, $\mathrm{POP}_{159 / 517}$ was less inhibited by $\mathrm{Zn}(\mathrm{II})$ and $\mathrm{Co}(\mathrm{II})$ compared to $\mathrm{Ni}(\mathrm{II})$ and $\mathrm{Cu}(\mathrm{II})$, which we hypothesize may reflect different preferred coordination geometries of the $\mathrm{M}(\mathrm{Bpy})_{\mathrm{n}}$ complexes (Supplementary Figure 3). In general, however, the response to these metals followed known equilibrium constants for $\mathrm{M}(\mathrm{Bpy})_{2}$ complex formation, ${ }^{37}$ with $\mathrm{Zn}(\mathrm{II})$ showing the weakest degree of inhibition or activation compared to the others, which have comparable equilibrium constants. In future experiments, we therefore used $\mathrm{Ni}(\mathrm{II})$, which has the highest equilibrium constant for $\mathrm{M}(\mathrm{Bpy})_{2}$ complex formation and was experimentally observed to have robust inhibition of multiple POP variants.

Our screening approach was then adapted to assay for reversibility by adding a competitive chelator, ethylenediaminetetraacetic acid (EDTA). EDTA formation constants for complexation with $\mathrm{Ni}(\mathrm{II}), \mathrm{Cu}(\mathrm{II}), \mathrm{Co}(\mathrm{II})$, and $\mathrm{Zn}(\mathrm{II})$ are $\sim 10^{16}-10^{18}$, which exceed values for $\mathrm{M}(\mathrm{Bpy})_{2}$ complex formation and thus should enable reversibility by competition. ${ }^{38}$ The panel of POP variants was 
incubated with 1000-fold excess metal, then exposed to $2 \mathrm{mM}$ EDTA, and finally assayed to measure activity. Nearly all enzymes tested displayed near-quantitative recovery of activity upon addition of EDTA, highlighting the reversibility of metal-BpyAla coordination (Supplementary Figure 4). $\mathrm{POP}_{167 / 517}, \mathrm{POP}_{169 / 510}$, and $\mathrm{POP}_{159 / 517}$ displayed robust switching between active and inhibited states based on the presence of $\mathrm{Ni}(\mathrm{II})$ and by the competitive chelation by EDTA (Figure $3 b)$. We note that switching occurred for all metals examined due to their strong binding affinity for EDTA. Interestingly, we also noted the reversibility of the activated $\mathrm{POP}_{167 / 513}$ variant, which further supports the unusual activation of this enzyme by the metal salts tested. These results highlight how our HTE workflow facilitated rapid identification of POP variants that displayed reversible catalytic responses to divalent metals in a manner consistent with the formation of a $\mathrm{M}(\text { BpyAla })_{2}$ complex involving Bpy LGs.

a

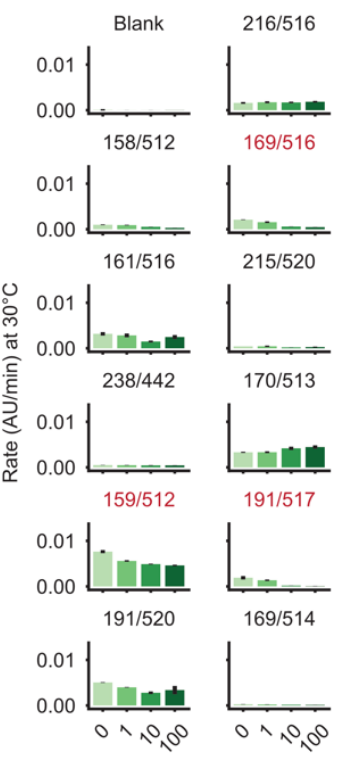

C

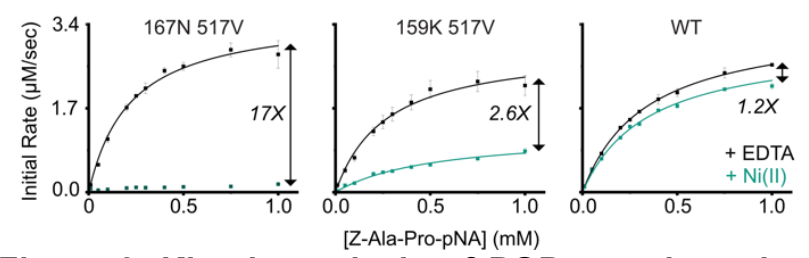

b
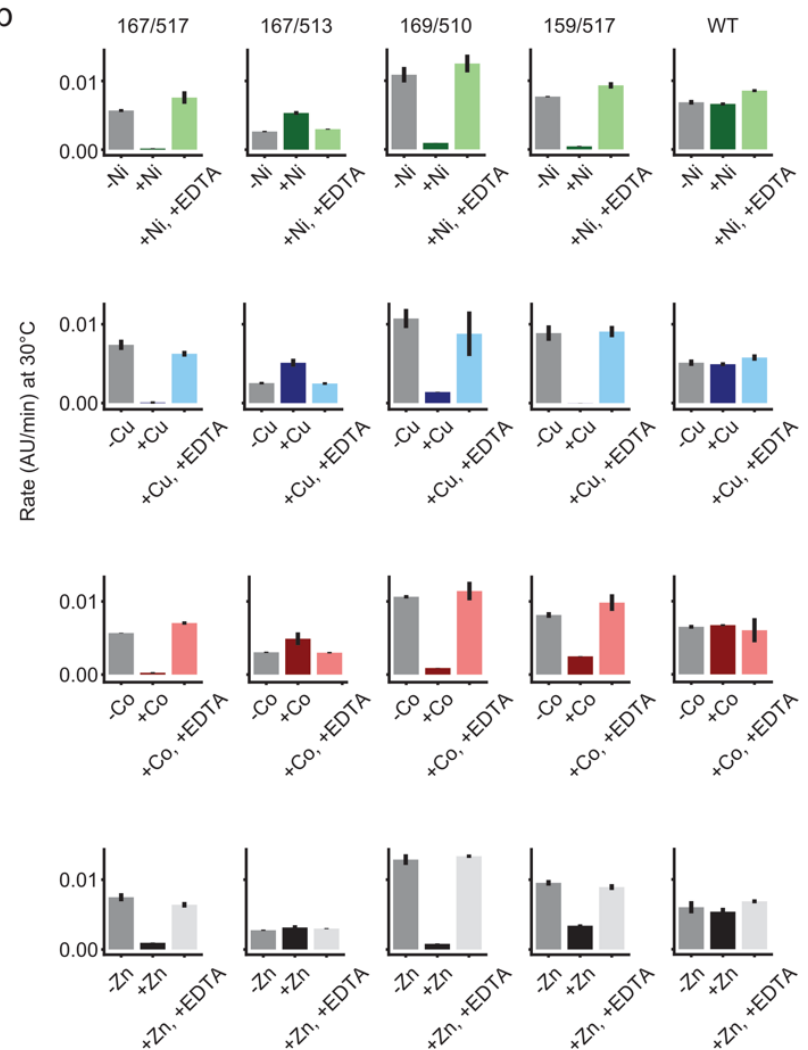

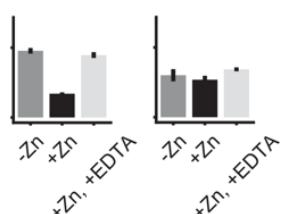

Figure 3. Kinetic analysis of $\mathrm{POP}_{\mathrm{X} / \mathrm{Y}}$ variants in response to divalent metals. (a,b) The activity of $\mathrm{POP}_{\mathrm{XYY}}$ variants from CFPS was assessed on Z-Ala-Pro-pNA. (a) Reaction rates (AU/min) at increasing $\mathrm{Ni}(\mathrm{II})$ concentrations $(0-100 \mu \mathrm{M})$. Inhibited variants are highlighted in red. The fold-changes between 0 and $10 \mu \mathrm{M}$ of $\mathrm{Ni}(\mathrm{II})$ for $\mathrm{POP}_{167 / 517}$ and $\mathrm{POP}_{159 / 513}$ are noted. (b) The reversibility of metal-dependent activity change through addition of EDTA is shown for select variants. (c) Steady-state kinetic assays performed at $85^{\circ} \mathrm{C}$ using purified enzymes $(\sim 20 \mathrm{nM})$ in the presence of either $1 \mathrm{mM}$ EDTA (black) or $5 \mu \mathrm{M} \mathrm{NiCl}{ }_{2}$ (green). Initial rates $(\mu \mathrm{M} / \mathrm{sec})$ are plotted versus substrate concentration $(\mathrm{mM})$, and data was fit, when appropriate, with the Michaelis-Menten equation. The fold-change between reaction rate at $1 \mathrm{mM}$ substrate is shown. Each data point represents the average of 3 replicates and error bars represent standard deviations.

\section{Functional characterization of a BpyAla POP switch}

We next studied the catalytic properties of the most promising variants identified via HTE. Purified variants were produced in yields of approximately $50 \mathrm{mg} / \mathrm{L}$ with minimal truncation products observed (Supplementary Fig. 5) and BpyAla incorporation confirmed by intact protein ESI-MS. 
Steady state kinetic parameters measured at $85^{\circ} \mathrm{C}$ showed that $\mathrm{POP}_{167 / 517}$ displayed a 17-fold change in activity in response to $\mathrm{Ni}$ (II) (Figure 3c), consistent with the high inhibition observed via HTE (Figure 3a). POP $159 / 517$ showed 2.6-fold inhibition using purified enzyme (Figure 3c), and the weaker inhibition of this variant allowed for determination of accurate kinetic parameters, revealing that $\mathrm{Ni}(\mathrm{II})$ increased $\mathrm{K}_{\mathrm{M}}$ and decreased $\mathrm{k}_{\text {cat }}$ (Table 1), resulting in a 4.5-fold decrease in catalytic efficiency $\left(\mathrm{k}_{\text {cat }} / \mathrm{K}_{\mathrm{M}}\right)$. Notably, $\mathrm{POP}_{167}$ and $\mathrm{POP}_{517}$ displayed only 1.1- and 1.4-fold changes in rate, respectively (Supplementary Fig. 6), demonstrating the necessity of two BpyAla residues for $\mathrm{Ni}(\mathrm{II})$-responsiveness, as expected for inhibition via the intended $\mathrm{Ni}(\mathrm{II})(\mathrm{BpyAla})_{2}$ linkage.

Table 1. Steady-state kinetic parameters for selected POP and Pluc variants.

\begin{tabular}{|c|c|c|c|c|c|c|}
\hline & \multicolumn{2}{|c|}{$K_{M}(\mu M)$} & \multicolumn{2}{|c|}{$k_{\text {cat }}\left(\sec ^{-1}\right)$} & \multicolumn{2}{|c|}{$\mathbf{V}_{\max }(\mathbf{R L U})$} \\
\hline Variant & $-\mathrm{Ni}(\mathrm{II})$ & $+\mathrm{Ni}(\mathrm{II})$ & $-\mathrm{Ni}(\mathrm{II})$ & $+\mathrm{Ni}(\mathrm{II})$ & $-\mathrm{Ni}(\mathrm{II})$ & $+\mathrm{Ni}(\mathrm{II})$ \\
\hline${ }^{2} \mathrm{POP}_{W T}$ & 335 & 345 & 172 & 152 & NA & NA \\
\hline${ }^{\mathrm{a}} \mathrm{POP}_{159 / 517}$ & 265 & 523 & 139 & 57 & NA & NA \\
\hline${ }^{a} P_{16 P_{167 / 517}}$ & 219 & NA & 181 & NA & NA & NA \\
\hline${ }^{\mathrm{D}} \mathrm{Pluc}{ }_{W T}$ & 1.47 & 1.19 & NA & NA & 40460 & 37940 \\
\hline${ }^{\mathrm{b}} \mathrm{Pluc}_{202 / 532}$ & 20 & 2.16 & NA & NA & 20091 & 999 \\
\hline${ }^{\mathrm{b}} \mathrm{Pluc}_{108 / 508}$ & 0.567 & 1.82 & NA & NA & 10890 & 1291 \\
\hline
\end{tabular}

${ }^{2}$ Reactions were conducted in triplicate using 0-1 mM Z-Ala-Pro-pNA and $20-21 \mathrm{nM}$ enzyme in $10 \% \mathrm{v} / \mathrm{v}$ DMSO/30 mM HEPES ( $\mathrm{pH} 7.4$ ) containing $0.8 \mathrm{M} \mathrm{NaCl}$ at $85^{\circ} \mathrm{C}$ for 1 minute. Average initial rates were determined by changes in absorbance over time at $410 \mathrm{~nm}$ using a calculated molar extinction coefficient for $p N A\left(7,126 \mathrm{M}^{-1} \mathrm{~cm}^{-1}\right)$. Kinetic parameters were determined by the non-linear regression function in OriginPro using the Michaelis-Menten equation. ${ }^{b}$ Reactions were conducted by mixing $1.1 \mu \mathrm{M}$ enzyme (preincubated with an equal volume of $1 \mathrm{mM} \mathrm{Ni}$ (II) when applicable) with $0-0.75 \mathrm{mM}$ D-luciferin in DMSO ( $5 \% \mathrm{v} / \mathrm{v}$ DMSO total) in $12.5 \mathrm{mM} \mathrm{HEPES} \mathrm{(pH} \mathrm{7.8),} 5 \mathrm{mM} \mathrm{MgSO}_{4}$, and $1 \mathrm{mM}$ ATP. Luminescence was read for $5 \mathrm{~min}$ at room temperature immediately after mixing. The maximum RLU values at each D-luciferin concentration, which describe the "glow" phase of the Pluc reaction mechanism, ${ }^{39}$ were fit to a MichaelisMenten equation with substrate inhibition. Max Rates describe apparent $\mathrm{V}_{\max }$ of Pluc in the glow phase.

We then characterized the dynamic range, robustness, and rate of $\mathrm{Ni}(\mathrm{II})$-mediated activity switching. Switching was performed over 24 alternating additions of either $\mathrm{Ni}$ (II) or EDTA for both WT POP and POP $167 / 517$. The enzymes were preincubated with $\mathrm{Ni}(\mathrm{II})$ or EDTA before an aliquot was removed to assess activity, which allowed the same enzyme sample to be switched between metallated and apo forms (Figure 4a). WT POP showed negligible inhibition by $\mathrm{Ni}(\mathrm{II})$ and a 1.9fold decrease in activity between the first and final switch, perhaps due to degradation of the enzyme from extended incubation in high concentrations of Ni/EDTA (Supplementary Figure 7). In contrast, $\mathrm{POP}_{167 / 517}$ demonstrated highly effective switching (Figure $4 \mathrm{~b}$ ). The enzyme is nearly inactive in the presence of $\mathrm{Ni}(\mathrm{II})$, full activity is recovered by addition of EDTA, and a 22-fold average dynamic range is maintained for the duration of activity cycling. Unlike the WT enzyme, no gradual decrease in the activity towards later cycles was observed, suggesting increased stability. Switching activity on or off was complete in $<5 \mathrm{~min}$, highlighting the efficiency of kinetically labile $\mathrm{Ni}(\mathrm{II})-\mathrm{BpyAla}$ dative bonding for reversibly controlling enzyme activity.

We next aimed to more directly probe $\mathrm{Ni}(\mathrm{II})$-BpyAla binding, since all evidence suggesting the involvement of the intended $\mathrm{M}(\text { BpyAla })_{2}$ linkage had thus far been inferred from the effects of added metal salts on $\mathrm{POP}_{X / Y}$ variant activity. Addition of $\mathrm{Ni}(\mathrm{II})$ to a solution of apo $\mathrm{POP}_{167 / 517}$ led to a mass spectrum with a low $\mathrm{m} / \mathrm{z}$ feature consistent with the presence of both one and two $\mathrm{Ni}$ (II) ions and a second high $\mathrm{m} / \mathrm{z}$ feature consistent with the presence of a single $\mathrm{Ni}$ (II) ion (Figure 4c). The higher $\mathrm{m} / \mathrm{z}$ of the latter feature indicates a lower charge state in which $\mathrm{POP}_{167 / 517}$ residues are less accessible for ionization, as would be expected in a more closed conformation, ${ }^{40}$ and the single metalation is consistent with coordination of $\mathrm{Ni}(\mathrm{II})$ by both BpyAla residues. Single metalation was also observed for both $\mathrm{POP}_{167}$ and $\mathrm{POP}_{517}$ in the presence of $\mathrm{Ni}(\mathrm{II})$, but only the 
low $\mathrm{m} / \mathrm{z}$ feature was observed for these, consistent with metal binding with an open conformation (Supplementary Figures 8 and 9).
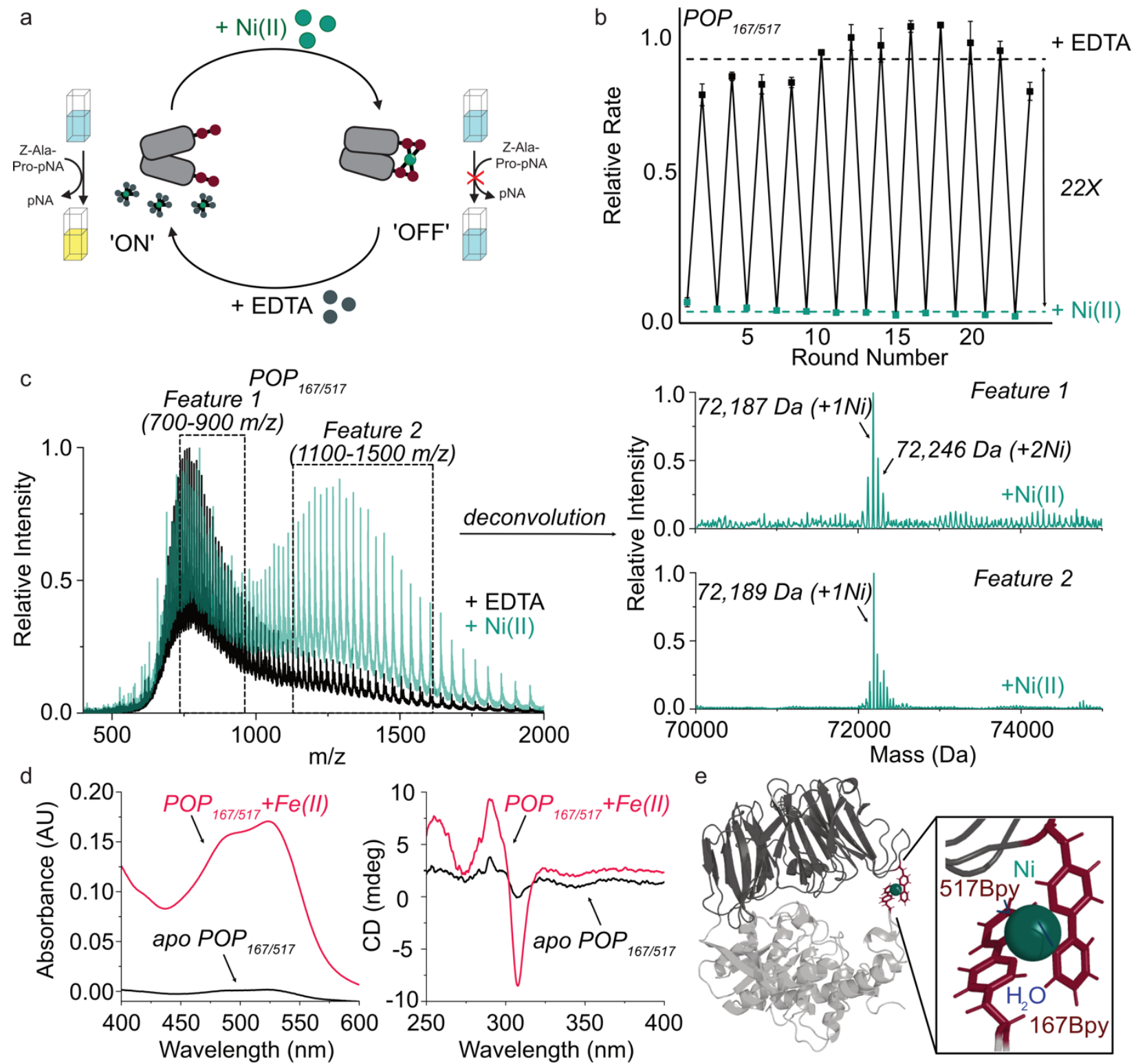

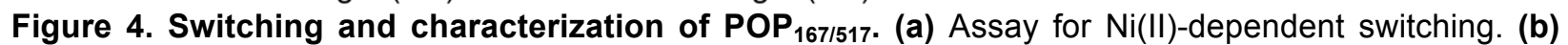
$\mathrm{Ni}(\mathrm{II})$-dependent switching as measured by the relative rate of Z-Ala-Pro-pNA hydrolysis upon addition of $\mathrm{Ni}(\mathrm{II})$ (green points) or EDTA (black points); average rates are shown as green or black dashed lines, respectively. Data points are averages of triplicate reactions and error bars represent standard deviations. (c) Intact protein ESI-MS data for POP $167 / 517$ in the presence of excess EDTA (black) or Ni(II) (green). Raw MS data (left) was deconvoluted (right) using $\mathrm{m} / \mathrm{z}$ windows of either $700-900$ or $1100-1500$ for the $\mathrm{Ni}(\mathrm{II})$ treated protein. (d) UV-Vis (left) and CD (right) spectra for apo (black) or Fe(II)-treated (pink) POP ${ }_{167 / 517}$ showing expected MLCT transition and intraligand charge transfer, respectively, in the presence of $\mathrm{Fe}(\mathrm{II})$. (e) A representative structure of $\mathrm{Ni}(\mathrm{II})$-bound $\mathrm{POP}_{167 / 517}$ from $\mathrm{MD}$ simulation shows coordination of two BpyAla residues and two waters to the $\mathrm{Ni}(\mathrm{II})$ center. 
Further support for the formation of a $\mathrm{M}(\text { BpyAla })_{2}$ linkage in $\mathrm{POP}_{167 / 517}$ was obtained from circular dichroism spectroscopy and UV-Vis spectroscopy (Figure $4 \mathrm{~d}$ ). While solutions of $\mathrm{Ni}(\mathrm{II})(\mathrm{bpy})_{\mathrm{n}}$ complexes at concentrations compatible with their formation in $\mathrm{POP}_{167 / 517}$ (i.e., $<0.5 \mathrm{mM}$ ) exhibit minimal absorbance in the UV-Vis region, ${ }^{41}$ the corresponding $\mathrm{Fe}(\mathrm{II})(\mathrm{bpy})_{\mathrm{n}}$ complexes possess a strong $\mathrm{MLCT}^{42}$ absorption at $\sim 520 \mathrm{~nm}$. This feature was observed upon addition of $\mathrm{Fe}(\mathrm{II})$ to solutions of apo $\mathrm{POP}_{167}, \mathrm{POP}_{517}$, and $\mathrm{POP}_{167 / 517}$, and the higher molar extinction coefficient of the latter is consistent with the formation of a $\mathrm{Fe}(\mathrm{II})(\text { BpyAla) })_{2}$ linkage (Supplementary Figure 10). Moreover, in the near UV spectral region associated with absorption from aromatic residues like BpyAla, the CD spectrum of $\mathrm{POP}_{167 / 517}$ has a local minimum and maximum at $308 \mathrm{~nm}$ and 290 $\mathrm{nm}$ (Supplementary Fig. 11), respectively, consistent with the expected intraligand $\pi$ to $\pi^{*}$ transition of the ncAA ${ }^{43}$. These Cotton effects are diagnostic of a chiral metal complex. ${ }^{44}$ The absence of this feature in $\mathrm{POP}_{167}$ or $\mathrm{POP}_{517}$ strongly suggests that both BpyAla residues bind $\mathrm{Fe}(\mathrm{II})$ in the $\mathrm{POP}_{167 / 517}$ scaffold to form the intended Fe(II)(BpyAla) $)_{2}$ linkage. The same high $\mathrm{m} / \mathrm{z}$ feature was observed by intact protein ESI-MS upon addition of $\mathrm{Fe}(\mathrm{II})$ to $\mathrm{POP}_{167 / 517}$ as was observed in the presence of $\mathrm{Ni}(\mathrm{II})$ (Supplementary Fig. 12), indicating that a similar linkage occurs in the presence of both $\mathrm{Ni}(\mathrm{II})$ and $\mathrm{Fe}(\mathrm{II})$. Together, these data suggest that bidentate metal coordination by two Bpy LGs to generate a M(II)(BpyAla) ${ }_{2}$ linkage as shown in Figure 4 e favors the closed conformation of $\mathrm{POP}_{167 / 517}$ and prohibits catalytic turnover.

\section{Extension to luciferase chemical switches}

To demonstrate the generality of the Bpy LG, we used the HTE workflow outlined above to engineer metal-responsive Photinus pyralis luciferase (Pluc) variants. Pluc is genetic reporter used in the life sciences, ${ }^{45}$ and the ability to switch its activity in response to metal ions may prove useful for biosensing applications. Structurally, Pluc requires a large conformational change between its $\mathrm{N}$ - and $\mathrm{C}$-terminal domains to first adenylate luciferin and then catalyze oxygendependent decarboxylation to form oxyluciferin and light. ${ }^{46} \mathrm{MD}$ simulations based on Pluc structures in both catalytic conformations were used to design 22 Pluc variants with BpyAla residues situated at sites that would allow reversible trapping in one conformation or the other (Figure 5a). ${ }^{46,47}$ Variants were solubly expressed using CFPS with average yields of $600 \mu \mathrm{g} / \mathrm{mL}$ as determined by ${ }^{14} \mathrm{C}$-leucine liquid scintillation counting, and full-length protein was obtained only in the presence of BpyAla, as observed by autoradiography (Supplementary Figure 13).

Metal-dependent regulation of Pluc activity was then examined by incubating the variants with different $\mathrm{Ni}$ (II) concentrations and assaying luciferase activity in a saturating amount of luciferin and ATP. Two variants, Pluc $_{202 / 532}$ and Pluc $108 / 508$, exhibited good activity ( $>25 \%$ WT activity) and were inhibited in a dose-dependent manner by $\mathrm{Ni}(\mathrm{II})$ (Figure $5 \mathrm{~b}$ ). Steady-state kinetic analysis of these variants in crude CFPS extract indicated that $\mathrm{V}_{\max }$ and $\mathrm{K}_{\mathrm{M}}$ of WT Pluc are only marginally affected by $\mathrm{Ni}(\mathrm{II})$, but $\mathrm{V}_{\max }$ values for $\mathrm{Pluc}_{202 / 532}$ and $\mathrm{Pluc}_{108 / 508}$ decrease by 20 -fold and 8.4-fold, respectively (Table 1 ). These results are consistent with the proposed conformational trapping preventing the enzyme from catalyzing either adenylation or oxidative decarboxylation. Interestingly, the $\mathrm{K}_{\mathrm{M}}$ for luciferin was reduced by a factor of 10 in the presence of $\mathrm{Ni}(\mathrm{II})$ for the Pluc $_{202 / 532}$ variant, which was selected based on the initial luciferin-binding form of the enzyme and could therefore reflect trapping of a conformation better suited to bind luciferin. Total catalytic efficiency $\left(V_{\max } / K_{M}\right)$ in the presence and absence of metal is 463 and $1005 \mathrm{RLU} / \mu \mathrm{M}$, respectively, for Pluc $_{202 / 532}$ and 709 and $19210 \mathrm{RLU} / \mu \mathrm{M}$, respectively, for $\mathrm{Pluc}_{108 / 508}$. Our results show that the Bpy LG can be used to regulate the activity of structurally distinct enzymes that catalyze unrelated chemical reactions in a stimulus-driven manner. 

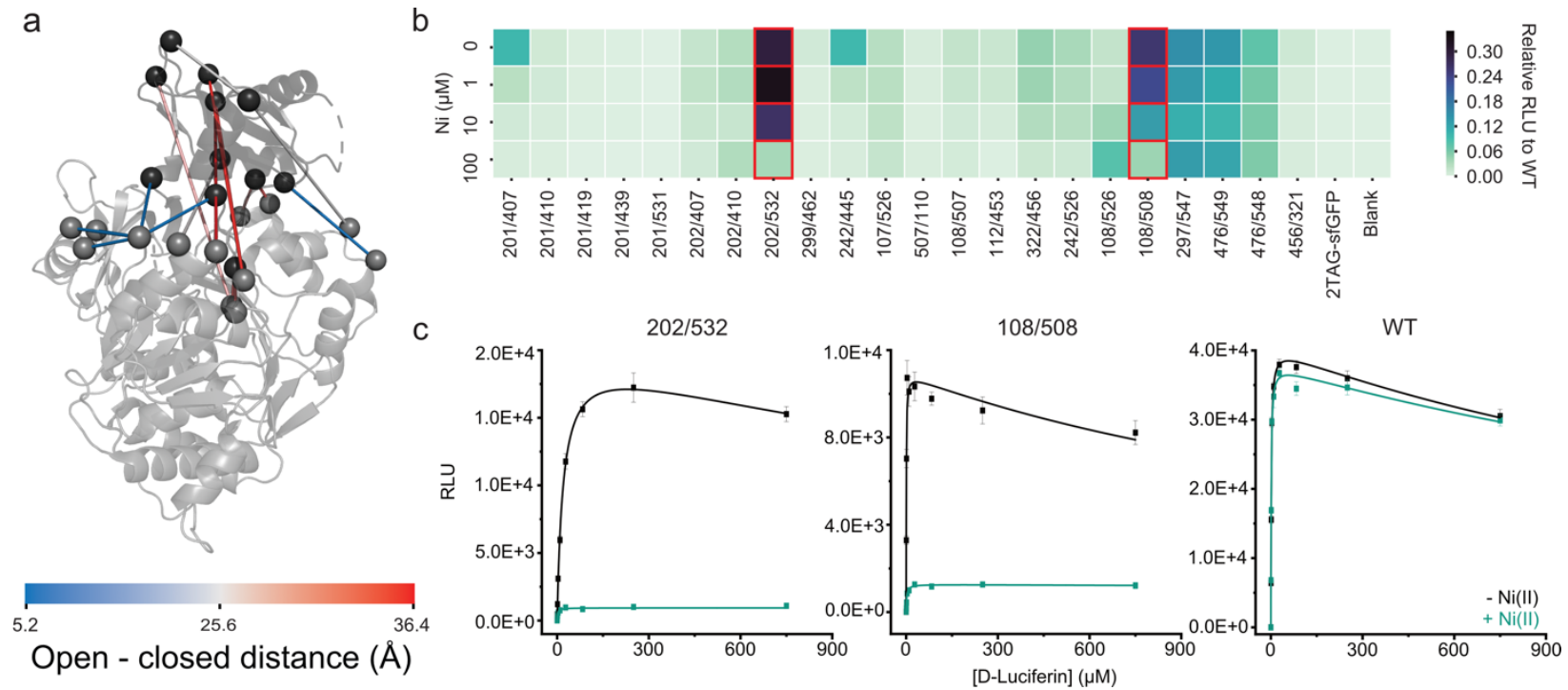

Figure 5. Implementation of LG-approach in firefly luciferase. (a) Locations of the final 22 LG pairs selected using the procedure outlined in Figure 2. (b) Pluc variants were synthesized using CFPS and activity of D-luciferin oxidation was assessed. Reaction rates (RLU) are shown in response to increasing $\mathrm{Ni}$ (II) concentrations $(0-100 \mu \mathrm{M})$ as a heat map. Inhibited variants are highlighted in red. (c) Steady-state kinetic assays were performed at room temperature with CFPS-produced enzyme variants Pluc $_{202 / 532}$, Pluc $_{108 / 508}$, and Pluc $W_{T}$ in either the absence (black) or presence of $\mathrm{Ni}(\mathrm{II})$ (green). Maximum rate (RLU) is plotted versus substrate concentration $(\mu \mathrm{M})$ and data was fit to a Michaelis-Menten equation with substrate inhibition using a custom python code. Each data point represents the average of three replicates and error bars represent standard deviations.

\section{Discussion}

In this study, we established an integrated computational and experimental workflow to incorporate a metal-responsive chemical switch into proteins. The workflow uses MD simulations to minimize experimental design validation and CFPS to synthesize designed variants in high yields and purities sufficient for direct assay. The latter technique enabled a rapid screening approach using HTE to prepare and monitor hundreds of designs exhibiting different phenotypes (e.g., activation, inactivation, and reversibility) in 384-well plates. The switch, comprising a pair of genetically encoded BpyAla residues that are strategically incorporated so that reversible metal coordination would bias enzyme conformational states, was benchmarked using two structurally distinct enzymes, Pfu POP and Pluc. The Bpy LG was incorporated into dozens of sites in these enzymes with high yields and had a minimal impact on the activity of functional variants in the absence of metal, highlighting its functional-orthogonality and potential utility for proteins that cannot accommodate large conformationally responsive domains or the introduction of new catalytic sites. The optimal POP variant displays up to a 20 -fold dynamic range in response to metal salts and can be switched on/off 24 times with no significant loss in activity, rivaling the best-performing reversible switches reported to date ${ }^{48}$. A similar dynamic range was observed in Pluc, showing the extensibility of LG regulation.

Kinetic, spectroscopic, and computational evidence indicates that switching by Bpy LG pairs involves reversible formation of the intended $\mathrm{M}(\mathrm{II})(\text { BpyAla })_{2}$ complex, which alters enzyme conformational landscapes to inhibit catalytic turnover. In this sense, the genetically encoded BpyAla residue allows facile access to the dynamic metal-ligand bonding with tunable bonding strength and specificity found in naturally occurring metalloproteins that have far more complex metal coordination environments and regulation transduction networks. ${ }^{49}$ BpyAla has been used 
to generate metallocofactors in artificial metalloproteins ${ }^{50}$ and metalloenzymes ${ }^{51}$, to stabilize protein motifs like coiled coils, ${ }^{52}$ and to template protein self-assembly, ${ }^{53}$ highlighting its propensity to form stable $\mathrm{M}(\text { BpyAla })_{n}$ complexes in a variety of protein contexts. This ability likely underpins the high stability of $\mathrm{POP}_{167 / 517}$ relative to WT POP during activity switching even at elevated temperatures and high salt concentrations and suggests that $\mathrm{M}(\mathrm{II})(\mathrm{BpyAla})_{2}$ complex formation plays a dual structural/functional role similar to metal binding in many natural ${ }^{54}$ and some artificial metalloenzymes ${ }^{55}$. Despite its thermodynamic stability, reversible BpyAla-metal binding at domain interfaces distal to enzyme active sites enables metal-responsive ${ }^{30}$ allosteric control over catalysis.

Even given the excellent switching properties exhibited by $\mathrm{POP}_{167 / 517}$, several observations suggest that significant improvements to LG switching could be realized. For example, Bpy LG pairs led to the intended metal-dependent inactivation in most POP variants, but some variants were activated (e.g., POP $167 / 513$ ). In addition, while the design process outlined in Figure 2 included geometric constraints from the crystal structures of $\mathrm{Ni}(\mathrm{II})(\mathrm{Bpy})_{2}$ complexes, several variants displayed modest specificity for other metal ions (Supplementary Figure 3). MD simulations also suggest that metal coordination to proximal canonical amino acids like Asn can occur (Supplementary Figure 14). Such interactions, combined with differential Bpy coordination enforced by the POP scaffold, could increase metal affinity or specificity or give rise to unique phenotypes, like the activation observed for $\mathrm{POP}_{167 / 513}$. These findings suggest that metal specificity and regulation behavior could be improved using geometric constraints for different metals, including canonical protein residues in switch designs, and using directed evolution to optimize emergent functions ${ }^{7-10}$. More broadly, while metal-ligand binding by the Bpy LG provides several unique advantages for switching, the methods developed here can be extended to engineer other protein switches involving LGs that respond to different stimuli. These efforts will be enabled by the availability of orthogonal aminoacyl transfer RNA (tRNA) synthetase (aaRS):tRNA pairs suitable for LG incorporation ${ }^{56,57}$ and improved methods for incorporating two unique $\mathrm{ncAAs}^{58-61}$.

Looking forward, we anticipate that genetically encoded chemical switches installed into proteins using the integrated computational/experimental approach described here will enable new strategies for protein engineering and synthetic biology. This will expand opportunities for controlling multi-enzyme biocatalysis ${ }^{3}$, in vivo sensing ${ }^{19}$, and other applications ${ }^{20}$ where spatial and temporal regulation of protein function is critical.

\section{Methods}

\section{High-Throughput Screening and Analysis of POP Variants}

CFPS reactions were performed to synthesize all proteins, including WT POP, the entire panel of POP variants, and 2TAG-sfGFP. Only Strepll-tagged enzymes were used for the high-throughput experiments. Blank reactions to dilute reactions to be equimolar were set up in parallel. After reaction completion, CFPS reactions were heat-treated at $75{ }^{\circ} \mathrm{C}$ for 15 minutes as a crude purification. Insoluble components were pelleted at $20,000 \times \mathrm{g}$ for 10 minutes at $4{ }^{\circ} \mathrm{C}$. The supernatant containing POP enzymes was diluted to $1 \mu \mathrm{M}$ using blank CFPS reactions as diluent. $4.5 \mu \mathrm{L}$ of POP enzymes were then mixed with $22.5 \mu \mathrm{L}$ of $2 \mathrm{X}$ POP Buffer (60 mM HEPES pH 7.4, $1.6 \mathrm{M} \mathrm{NaCl}$ ) $4.5 \mu \mathrm{L}$ of $0-1 \mathrm{mM}$ metal (Nickel(II) Sulfate Hexahydrate, Copper(II) Sulfate Pentahydrate, Cobalt(II) Chloride Hexahydrate, or Zinc(II) Chloride), and $13.5 \mu \mathrm{L}$ of water. The mixture was equilibrated on ice for $2 \mathrm{hr}$. For reversibility screening, $1.8 \mu \mathrm{L}$ of $50 \mathrm{mM}$ EDTA pH 8.0 was added and then incubated for an additional hour on ice. During the incubations, $1.2 \mu \mathrm{L}$ of 25 $\mathrm{mM}$ Z-Ala-Pro-pNA in DMSO was spotted into each well of a clear, flat-bottom 384-well plate from 
a source plate using the Echo 550. After incubation on ice, the reaction mixture was split into three $13.5 \mu \mathrm{L}$ aliquots and pre-warmed to $30^{\circ} \mathrm{C}$. Using the Integra Viaflo, $10.8 \mu \mathrm{L}$ of the reaction mixture was dispensed into the substrate-containing 384-well plate and mixed thoroughly. The plate was quickly spun down and read on a pre-warmed plate reader at $30{ }^{\circ} \mathrm{C}$ at $410 \mathrm{~nm}$ for two hours. Kinetic curves were analyzed using a custom Python script. Briefly, this script requires two input files: (i) A minimally formatted raw data CSV and (ii) a descriptor CSV that annotates reaction conditions for each well. The script calculates rate by conducting a linear regression over a sliding window of five timepoints and calculates an average and standard deviation between all replicates. Finally, it identifies and plots the maximum slope for each reaction condition. An example of the script is included in the Supplementary Information.

\section{Switching Assay of POP Variants}

The switching of activity between 'on' and 'off' states was performed using a modified version of the kinetic assays described in the Supplementary Information. $500 \mu \mathrm{L}$ of a $1 \mu \mathrm{M}$ stock of protein (in $\mathrm{MQ} \mathrm{H} \mathrm{H}_{2} \mathrm{O}$ ) was incubated at $55{ }^{\circ} \mathrm{C}$ with shaking $(750 \mathrm{rpm})$ for the entirety of the assay. For the first round, $1 \mu \mathrm{L}$ of $\mathrm{NiCl}_{2}$ solution $(10 \mathrm{mM})$ was added to the protein stock and the sample was incubated for 2 minutes. An aliquot of protein was removed from the stock and added to a quartz cuvette containing buffer. The amount of protein added to the reaction buffer was adjusted throughout the assay based on the changing concentration due to additions of $E D T A / \mathrm{NiCl}_{2}$ (Supplementary Table 7). The cuvette was then incubated at $85^{\circ} \mathrm{C}$ for 2 minutes. At the same time, $2 \mu \mathrm{L}$ of EDTA (10 mM, pH 8.0) was added to the protein stock for the second round and a 2-minute incubation was started. After incubating the cuvette, the reaction was initiated by addition of $100 \mu \mathrm{L}$ of Z-Ala-Pro-pNA (10 mM in DMSO) and the solution was mixed by pipetting up and down several times. The reaction was monitored by following the formation of $p$ NA with absorbance measurements (at $410 \mathrm{~nm}$ ) every 6 seconds for 1 minute. Initial rates were determined by converting absorbance values over time to concentrations of time using the molar extinction coefficient $\left(\varepsilon_{410}=7,126 \mathrm{M}^{-1} \mathrm{~cm}^{-1}\right)$ in Excel. Simultaneously, an aliquot of protein (20.1 $\mu \mathrm{L}$ ) was removed from the protein stock solution and added to a cuvette containing buffer and was incubated at $85^{\circ} \mathrm{C}$ for 2 minutes. This cycle was repeated in the same manner by alternating additions of $\mathrm{NiCl}_{2}$ and EDTA. Final concentrations of components in the reaction were as follows: $30 \mathrm{mM}$ HEPES (pH 7.4), $100 \mathrm{mM} \mathrm{NaCl}, 20 \mathrm{nM}$ enzyme, 0.2-30 mM NiCl , 0-41 mM EDTA, 1.00 $\mathrm{mM}$ Z-Ala-Pro-pNA, and $10 \%(\mathrm{v} / \mathrm{v})$ DMSO. All data were collected in triplicate and averaged. Relative rates were determined by dividing each average initial rate by the maximum average rate collected for that data set so that the highest relative rate was 1 . The relative initial rates were plotted versus round to assess the switching of the systems. Error bars represent propagated standard deviations.

Complete materials and methods are available in the Supplementary Information.

\section{References}

1. Davidi, D., Longo, L. M., Jabłońska, J., Milo, R. \& Tawfik, D. S. A Bird's-Eye View of Enzyme Evolution: Chemical, Physicochemical, and Physiological Considerations. Chem. Rev. 118, 8786-8797 (2018).

2. Cornish-Bowden, A. Understanding allosteric and cooperative interactions in enzymes. FEBS J. 281, 621-632 (2014).

3. Claaßen, C., Gerlach, T. \& Rother, D. Stimulus-Responsive Regulation of Enzyme Activity for One-Step and Multi-Step Syntheses. Adv. Synth. Catal. 361, 2387-2401 (2019).

4. Bell, E. L. et al. Biocatalysis. Nat. Rev. Methods Primers 1, 46 (2021).

5. Devine, P. N. et al. Extending the application of biocatalysis to meet the challenges of drug development. Nat. Rev. Chem. 2, 409-421 (2018). 
6. Taylor, N. D. et al. Engineering an allosteric transcription factor to respond to new ligands. Nat. Methods 13, 177-183 (2016).

7. Buller, A. R. et al. Directed evolution of the tryptophan synthase $\beta$-subunit for stand-alone function recapitulates allosteric activation. PNAS 112, 14599-14604 (2015).

8. Jiménez-Osés, G. et al. The role of distant mutations and allosteric regulation on LovD active site dynamics. Nat. Chem. Biol. 10, 431-436 (2014).

9. Otten, R. et al. Rescue of conformational dynamics in enzyme catalysis by directed evolution. Nat. Commun. 9, 1314 (2018).

10. Leander, M., Yuan, Y., Meger, A., Cui, Q. \& Raman, S. Functional plasticity and evolutionary adaptation of allosteric regulation. PNAS 117, 25445-25454 (2020).

11. Raman, S., Taylor, N., Genuth, N., Fields, S. \& Church, G. M. Engineering allostery. Trends in Genetics 30, 521-528 (2014).

12. Fan, Y., Cross, P. J., Jameson, G. B. \& Parker, E. J. Exploring modular allostery via interchangeable regulatory domains. PNAS 115, 3006-3011 (2018).

13. Dagliyan, O., Dokholyan, N. V. \& Hahn, K. M. Engineering proteins for allosteric control by light or ligands. Nat. Protoc. 14, 1863-1883 (2019).

14. Shaaya, M. et al. Light-regulated allosteric switch enables temporal and subcellular control of enzyme activity. Elife 9, 1 (2020).

15. Tullman, J., Nicholes, N., Dumont, M. R., Ribeiro, L. F. \& Ostermeier, M. Enzymatic protein switches built from paralogous input domains. Biotechnol. Bioeng. 113, 852-858 (2016).

16. Langan, R. A. et al. De novo design of bioactive protein switches. Nature $572,205-210$ (2019).

17. Quijano-Rubio, A. et al. De novo design of modular and tunable protein biosensors. Nature 591, 482-487 (2021).

18. Stein, V. \& Alexandrov, K. Synthetic protein switches: Design principles and applications. Trends in Biotechnology 33, 101-110 (2015).

19. Guo, Z. et al. Generalizable Protein Biosensors Based on Synthetic Switch Modules. JACS 141, 8128-8135 (2020).

20. Dueber, J. E., Yeh, B. J., Chak, K. \& Lim, W. A. Reprogramming control of an allosteric signaling switch through modular recombination. Science 301, 1904-1908 (2003).

21. Furikado, Y. et al. Universal Reaction Mechanism of Boronic Acids with Diols in Aqueous Solution: Kinetics and the Basic Concept of a Conditional Formation Constant. Chem. Eur. J. 20, 13194-13202 (2014).

22. Bhat, V. T. et al. Nucleophilic catalysis of acylhydrazone equilibration for protein-directed dynamic covalent chemistry. Nat. Chem. 2, 490-497 (2010).

23. Kaes, C., Katz, A., \& Hosseini, M. W. Bipyridine: The Most Widely Used Ligand. A Review of Molecules Comprising at Least Two 2,2'-Bipyridine Units. Chem. Rev. 100, 3553-3590 (2000).

24. Young, D. D. \& Schultz, P. G. Playing with the Molecules of Life. ACS Chem. Biol. 13, 854870 (2018).

25. Hoppmann, C., Maslennikov, I., Choe, S. \& Wang, L. In Situ Formation of an Azo Bridge on Proteins Controllable by Visible Light. JACS. 137, 11218-11221 (2015).

26. Cao, W. et al. A General Supramolecular Approach to Regulate Protein Functions by Cucurbit[7]uril and Unnatural Amino Acid Recognition. Angew. Chemie Int. Ed. 60, 1119611200 (2021).

27. Luo, J., Liu, Q., Morihiro, K. \& Deiters, A. Small-molecule control of protein function through Staudinger reduction. Nat. Chem. 8, 1027-1034 (2016).

28. Li, J., Jia, S. \& Chen, P. R. Diels-Alder reaction-triggered bioorthogonal protein decaging in living cells. Nat. Chem. Biol. 10, 1003-1005 (2014).

29. Des Soye, B. J., Gerbasi, V. R., Thomas, P. M., Kelleher, N. L. \& Jewett, M. C. A Highly Productive, One-Pot Cell-Free Protein Synthesis Platform Based on Genomically Recoded 
Escherichia coli. Cell Chem. Biol. 26, 1743-1754.e9 (2019).

30. Reyes-Caballero, H., Campanello, G. C. \& Giedroc, D. P. Metalloregulatory proteins: Metal selectivity and allosteric switching. Biophys. Chem. 156, 103-114 (2011).

31. Harris, M. N., Madura, J. D., Ming, L. J. \& Harwood, V. J. Kinetic and Mechanistic Studies of Prolyl Oligopeptidase from the Hyperthermophile Pyrococcus furiosus. J. Biol. Chem. 276, 19130-19137 (2001).

32. Ellis-Guardiola, K. et al. Crystal Structure and Conformational Dynamics of Pyrococcus furiosus Prolyl Oligopeptidase. Biochemistry 58, 1616-1626 (2019).

33. Xie, J., Liu, W. \& Schultz, P. G. A Genetically Encoded Bidentate, Metal-Binding Amino Acid. Angew. Chemie Int. Ed. 46, 9239-9242 (2007).

34. Silverman, A. D., Karim, A. S. \& Jewett, M. C. Cell-free gene expression: an expanded repertoire of applications. Nat. Rev. Genet. 21, 151-170 (2020).

35. Martin, R. W. et al. Cell-free protein synthesis from genomically recoded bacteria enables multisite incorporation of noncanonical amino acids. Nat. Commun. 9, 1203 (2018).

36. Hammerling, M. J., Krüger, A. \& Jewett, M. C. Strategies for in vitro engineering of the translation machinery. Nucleic Acids Res. 48, 1068-1083 (2020).

37. Smith, R. M. \& Martell, A. E. Critical Stability Constants Volume 2: Amines 235-237 (Plenum Press, New York, 1975).

38. Smith, R. M. \& Martell, A. E. Critical Stability Constants Second Supplement 96-99 (Plenum Press, New York, 1989).

39. Pozzo, T., Akter, F., Nomura, Y., Louie, A. Y. \& Yokobayashi, Y. Firefly Luciferase Mutant with Enhanced Activity and Thermostability. ACS Omega 3, 2628-2633 (2018).

40. Kafader, J. O. et al. Native vs Denatured: An in Depth Investigation of Charge State and Isotope Distributions. J. Am. Soc. Mass Spectrom. 31, 574-581 (2020).

41. Vander Griend, D. A., Bediako, D. K., DeVries, M. J., DeJong, N. A., \& Heeringa, L. P. Detailed Spectroscopic, Thermodynamic, and Kinetic Characterization of Nickel(II) Complexes with 2,2'-Bipyridine and 1,10-Phenanthroline Attained via EquilibriumRestricted Factor Analysis. Inorg. Chem. 47, 656-662 (2007).

42. Mason, S. F. The electronic spectra and optical activity of phenanthroline and dipyridyl metal complexes. Inorganica Chim. Acta Rev. 2, 89-109 (1968).

43. Meyer, T. J. Photochemistry Of Metal Coordination Complexes: Metal To Ligand Charge Transfer Excited States. Pure Appl. Chem. 58, 1193-1206 (1986).

44. Gillard, R. D. Progress in Inorganic Chemistry, Volume 7: The Cotton Effect in Coordination Compounds, 215-276 (John Wiley \& Sons Inc., Hoboken, 1966).

45. Thorne, N., Inglese, J. \& Auld, D. S. Illuminating insights into firefly luciferase and other bioluminescent reporters used in chemical biology. Chem. Biol. 17, 646-657 (2010).

46. Sundlov, J. A., Fontaine, D. M., Southworth, T. L., Branchini, B. R. \& Gulick, A. M. Crystal structure of firefly luciferase in a second catalytic conformation supports a domain alternation mechanism. Biochemistry 51, 6493-6495 (2012).

47. Conti, E., Franks, N. P. \& Brick, P. Crystal structure of firefly luciferase throws light on a superfamily of adenylate-forming enzymes. Structure 4, 287-298 (1996).

48. Zhang, C. et al. Reversible $\mathrm{Ca}{ }^{2+}$ Switch of An Engineered Allosteric Antioxidant Selenoenzyme. Angew. Chemie Int. Ed. 53, 13536-13539 (2014).

49. Nastri, F. et al. Engineering Metalloprotein Functions in Designed and Native Scaffolds. Trends Biochem. Sci. 44, 1022-1040 (2019).

50. Mills, J. H. et al. Computational design of a homotrimeric metalloprotein with a trisbipyridyl core. PNAS 113, 15012-15017 (2016).

51. Drienovská, I., Rioz-Martínez, A., Draksharapu, A. \& Roelfes, G. Novel artificial metalloenzymes by in vivo incorporation of metal-binding unnatural amino acids. Chem. Sci. 6, 770-776 (2015).

52. Luo, X., Wang, T. S. A., Zhang, Y., Wang, F. \& Schultz, P. G. Stabilizing Protein Motifs with 
a Genetically Encoded Metal-Ion Chelator. Cell Chem. Biol. 23, 1098-1102 (2016).

53. Yang, M. \& Song, W. J. Diverse protein assembly driven by metal and chelating amino acids with selectivity and tunability. Nat. Commun. 10, 5545 (2019).

54. Holm, R. H., Kennepohl, P., \& Solomon, E. I. Structural and Functional Aspects of Metal Sites in Biology. Chem. Rev. 96, 2239-2314 (1996).

55. Upp, D. M. et al. Engineering Dirhodium Artificial Metalloenzymes for Diazo Coupling Cascade Reactions. Preprint at https://chemrxiv.org/engage/chemrxiv/articledetails/60c9e3b1551c4f6c67c4c30a (2021).

56. Bryson, D. I. et al. Continuous directed evolution of aminoacyl-tRNA synthetases. Nat. Chem. Biol. 13, 1253-1260 (2017).

57. Amiram, M. et al. Evolution of translation machinery in recoded bacteria enables multi-site incorporation of nonstandard amino acids. Nat. Biotechnol. 33, 1272-1279 (2015).

58. Tharp, J. M., Vargas-Rodriguez, O., Schepartz, A. \& Söll, D. Genetic Encoding of Three Distinct Noncanonical Amino Acids Using Reprogrammed Initiator and Nonsense Codons. ACS Chem. Biol. 16, 766-774 (2021).

59. Chatterjee, A., Sun, S. B., Furman, J. L., Xiao, H. \& Schultz, P. G. A Versatile Platform for Single- and Multiple-Unnatural Amino Acid Mutagenesis in Escherichia coli. Biochemistry 52, 1828-1837 (2013).

60. Torre, D. de la \& Chin, J. W. Reprogramming the genetic code. Nat. Rev. Genet. 22, 169184 (2020).

61. Kofman, C., Lee, J. \& Jewett, M. C. Engineering molecular translation systems. Cell Syst. 12, 593-607 (2021).

\section{Acknowledgments:}

This study was supported by the U.S. Army Research Laboratory and the U.S. Army Research Office under Contracts/Grants W911NF-18-1-0034 and W911NF-15-1-0334 (J.C.L.), W911NF18-1-0181 (M.C.J.), and under Grant Number W911NF-18-1-0200 (J.C.L and M.C.J.); the David and Lucile Packard Foundation (M.C.J.); and the Camille Dreyfus Teacher-Scholar Program (J.C.L. and M.C.J.). Y.S.Z gratefully acknowledges receipt of a predoctoral fellowship from the Graduate Training Program in Quantitative and Chemical Biology at Indiana University (T32 GM131994). K.S acknowledges support from a predoctoral fellowship from Chemistry of Life Processes Institute, supported by the National Institute of General Medical Sciences of the National Institutes of Health (T32 GM105538). A.H. acknowledges the Department of Defense National Defense Science and Engineering Graduate Fellowship Program (NDSEG-36373). We thank Mr. Matthew Jordan for performing ICP-MS measurements; Dr. Jonathan Trinidad for assistance with intact protein ESI-MS; Dr. Giovanni Gonzalez-Gutierrez for assistance with various instrumentation in the IU Physical Biochemistry Instrumentation Facility; Prof. Amar Flood for access to a UV-Vis spectrophotometer; and Mr. Saman Shafaie and Dr. Benjamin Owen for training on ESI-MS instruments at IMSERC in NU. The content is solely the responsibility of the authors and does not necessarily represent the official views of the National Institutes of Health.

\section{Author contributions:}

Y.S.Z. identified Pluc as a model system for LG switching; developed activity assays for POP and Pluc; designed the POP activity switching experiment; conducted steady state kinetic analysis, activity switching, and characterization of metal binding by POP BpyAla variants; analyzed data; and wrote the manuscript.

K.S. developed CFPS protocols to incorporate BpyAla into POP, developed HT assays for POP and Pluc activation, inhibition, and switching; conducted all HT LG design screens; conducted all kinetic analysis of Pluc variant activity; analyzed data; and wrote the manuscript.

Y.L. conducted all M.D. simulations and modeling and analyzed data.

A.H. assisted in developing HT assays for POP mutant screening. 
B.L. synthesized BpyAla.

B.R. conceived and directed the project, analyzed data, and wrote the manuscript.

M.C.J. conceived and directed the project, analyzed data, and wrote the manuscript.

J.C.L. conceived and directed the project, analyzed data, and wrote the manuscript.

\section{Competing interests:}

M.C.J. is a cofounder of SwiftScale Biologics, Stemloop, Inc., Design Pharmaceuticals, and Pearl Bio. M.C.J.'s interests are reviewed and managed by Northwestern University in accordance with their conflict of interest policies. All other authors declare no competing interests.

\section{Data and materials availability:}

Data are available from the authors upon request. 